\title{
Directions and mechanisms of globalization impact on institutional structure of society
}

\author{
Mikhail Nikolaev ${ }^{1 *}$, Marina Magdeeva ${ }^{2}$ \\ ${ }^{1}$ Russian University of Cooperation, Kazan Cooperation Institute (Branch), 420081, Russian \\ Federation, Kazan, Russia \\ ${ }^{2}$ Russian University of Cooperation, Kazan Cooperation Institute (Branch), 420081, Russian \\ Federation, Kazan, Russia
}

\begin{abstract}
The article studies the problematic issues of essence and content of globalization process, directions and mechanisms of its impact on institutional structure of society. At the same time, globalization is viewed as a complex complicated and contradictory process not only increasing the dependence between socioeconomic and economic systems of individual countries, but also as a factor directly changing the course of development vector of institutional structures that sets a new trajectory of their movement. It is important to analyze the impact of globalization on the institutional structure through various by nature institutions - formal ones, which at each stage of development are artificially created, as a rule, by the state, and informal ones (traditions, social conventions, customs, etc.), the mechanism of globalization impact on which directly links with its impact on the property of fractality or self-similarity of socio-economic systems. Some contradictions that arise in the process of the mentioned interaction are considered and analyzed. The aim of the study is to identify the mechanisms of globalization influence on institutional structure of society and the limits of its positive impact on development of this society. Methods of the study: abstract-logical; theory of nonlinear dynamics; historical and economic analysis.
\end{abstract}

\section{Introduction}

Globalization, apart from its currently formed theoretical models and approaches to the study of content, is an objective, multi-level and at the same time contradictory process of convergence and unification of economic, socio-economic and social systems of different countries of the world. However, it is an important factor of education in these countries new institutions or transforms existing according to the requirements of functioning of the world economy and, therefore, the factor of changes in the institutional structure of States, asking at each stage, new path of its development. If we consider the phenomenon of globalization through the prism of its models, we will get something more detailed, and perhaps a slightly different picture of its content with a different emphasis, but generally does not contradict the above definition.

\footnotetext{
* Corresponding author: mnikolae@yandex.ru
} 
Many researchers attribute the beginning of globalization to the end of the XIX century, considering it as a qualitatively new stage in the evolution of the processes of internationalization, characterized by the development of mainly trade activities between countries. By this time, however, these processes had already spread from the sphere of circulation to industrial relations, thus giving internationalization a new content [1-3]. At the same time, there are alternative views on the content and duration of the global globalization process. Therefore, we consider briefly some approaches and models in order to show that, irrespective of their degree of correspondence with reality, globalization, however defined, is inextricably linked with the formation of new institutions and the impact on the institutional structure of society, and to analyze the mechanisms of this effect. At the end of the XX century an attempt was made to group the most interesting of the models in some respects. The first of these groups, called models of the global system, included the results of studies by I. Wallerstein, E. Giddens and L. Sclair. Common to them is that they are all based on the developed I. Wallerstein world-system analysis, the purpose of which is to study the evolution of individual societies and social systems.

I. Wallerstein considers globalization as a long process, going back 5 centuries, and its development is associated with the theory of long waves N.D. Kondratiev. The worldeconomy in his model consists of several groups of different societies, which form the centre, buffer half-periphery and periphery of the system. The center and the periphery are characterized by a relationship of dependence and exploitation. And the countries of the semiperiphery - relations of a mixed type, acting in relation to one as the center, and to others the periphery. The author referred to them, in particular, the USSR and Eastern European countries [4]. The Analysis shows that the world-economy of I. Wallerstein can be interpreted as a new complex supranational global institution of the modern era, which has a significant impact on the institutional structure of all States.

E. Giddens defines globalization as the spread of social relations in the world, connecting together all the distant places, considering these relations in several institutional dimensions: the world capitalist system; an interconnected set of national States; the military world order; the inter-country division of labor [5]. It is obvious that the development of social relations under this model is accompanied by the formation in countries of a large number of new institutions that regulate this development and thus, as in the Wallerstein model, changing the institutional structure of States.

L. Skler examines transnational practices that act and form at the economic, political and ideological and cultural levels of their basic institutions that stimulate globalization. On the economic level, the Institute for transnational corporations, the political Institute of the capitalist class, on ideological and - consumerism, understood as ideologized economic, or commercialized ideological practice [6].

The second groups of models, the global sociality include models R. Robertson, W. Beck, G. Therborn. Their common feature is the analysis of globalization as structural changes primarily in interpersonal interactions and in the minds of people, meaning the formation of their global consciousness. At the same time, R. Robertson believes that such consciousness is ultimately no less important for the world to become a "single socio-cultural place" [7].

W. Beck develops the concept of transnational social space, close in meaning to the" single socio-cultural place» and expresses an important idea that the processes of globalization occurring in the economy, politics, culture, etc., each have its own logic of development and are not reduced to each other [8].

G. Therborn highlights in the development of globalization six waves, characterized by their own institutional dimension: the religious; military-political; economic; cultural [9]. It is not difficult to see that each such wave is associated with a change in the institutional structure of society. 
The third group, called models of deterritorialization, includes the development of A. Appadurai and M. Waters, which are based on the analysis of changes in the sphere of culture.

A. Appadurai considers globalization in the context of loss of communication for social change with a particular territory, believing that in the mass migration of people, migrant workers, refugees, etc. the formation of communities with their ideology, not tied to any state, and their own bureaucracy, which are elements of the new structure "in the framework of the emerging post-national order" [10] and the formation of such communities is again accompanied by a major change in the institutional structure of the state.

M. Waters consider culture to be the most globalized sphere, since social relations in it are maximally symbolized and can occur without reference to the territory [11] and the globalization of culture through mediating links (simulacras Baudrillard), then transferred to the economy and politics, intensifying and there the development of similar processes of globalization and the formation of new institutions.

Thus, from the review and analysis of models, firstly, it is clear that the content of globalization, in a sense, can generally be seen as a process of formation of a new single (or similar) system of institutions for all States, and its development is inseparable from the development and unification of the institutional structure of different States. Secondly, from the above review and analysis it follows the relevance of the study outlined in the article, as well as the need to continue the analysis of the mechanisms of the impact of globalization on the institutional structure of society.

\section{Methods}

The following research methods were used:

1) abstract-logical method, which is a specific tool of scientific knowledge and allowed not only to explore the content of the complex and contradictory process of globalization as a special economic category, but also its relationship with the institutional structure of States;

2) methods of the theory of nonlinear dynamics, which allowed, firstly, to consider the costs of economic dissipation, indicating, in particular, the degree of order or chaos of the economic system, as a possible criterion for the effectiveness of the new formal institutions created in the country; secondly, to reveal the content of the contradiction between the trends of globalization to unity and unification, on the one hand, and the possibilities of formation of new informal institutions, on the other;

3) methods of historical and economic analysis, which made it possible to consider the impact of globalization on the processes of creating new formal and informal institutions in society and changing its institutional structure not only in a logical but also a strict time sequence.

\section{Results and discussion}

\subsection{The Impact of globalization on the institutional structure of society through formal and informal institutions}

The impact of globalization on the institutional structure covers a large number of its relations and relations with institutions of different nature - formal and informal; different spheres of society - economic, political, social; different levels - national States and supranational, etc [12].

Let us consider some of these impacts in more detail, first through formal and informal institutions. The first, as noted above, are expressed in a variety of artificially set rules, and informal-in the" unwritten» norms-traditions, habits, culture, etc.

The impact of globalization on the institutional structure through formal institutions occurs, firstly, by expanding and simplifying the opportunities for their formation in the 
conditions of open economies and, as a consequence, by accelerating the processes of borrowing by some States from other ready-made effective institutions. Secondly, more often, through the simplification and acceleration of the processes of institutional diffusion, i.e. penetration of only certain norms or elements of some institutions into others, which normally occur slowly. Diffusion also plays a positive role in bringing formal rules closer together with informal norms of behavior in different countries, thereby enhancing the sustainability and effectiveness of their institutional systems [13]. On a massive scale, such borrowing and diffusion processes occurred in Russia and Eastern Europe during the transition to the market. Before the transition, they had a large number of informal norms, which are firmly rooted in the previous command and partly distribution systems. At the same time, a number of Eastern European countries retained some of the market institutions associated with small private property, and in Russia there was, in contrast, a very important role played here by a large-scale shadow sector of the economy, which is actually the pseudomarket.

The task was to create a full-fledged system of market institutions, which would become the basis of the new system. However, if in Eastern Europe this task, taking into account the initial conditions, including their institutional structure, significantly different from the Russian, as well as spiritual and cultural affinity with the developed market countries of Western Europe, was carried out more or less calmly, in Russia a different picture emerged. Here, the initial conditions were characterized by the presence of many informal norms inherited from the previous economic system and at all stages of the country's development, including today, in General, played no less, and often more important role than the formal ones.

Informal relations permeated (and continue to permeate today) all levels of the Russian economic system and management. Among them: firmly rooted in public opinion traditions and habit to solve many, and often most of the issues not on the basis of laws, but through informal arrangements; numerous systems of not always justified benefits; support for lossmaking businesses and many others that still continue to operate. They are very difficult to change, because they are rooted in deep layers of Russian centuries-old culture [14-15].

Moreover, the introduction by the state of new types of formal market institutions, which were intended to displace the informal norms of relations, actually encountered fierce resistance of the system, which often even led to the paradoxical phenomenon - their informal rebirth. An example is the attempt of the Russian government to introduce a system of progressive taxation, inherent in most Western market countries, but which eventually did not take root and had to be abandoned.

As a criterion for the effectiveness of existing and emerging in the process of transformation of new formal institutions is usually proposed to use the value of the relevant transaction costs, although no less important role is played by the dissipative costs (or the costs of economic dissipation). The Last mean always taking place in any economic and social system, irrespective of the level of its technical and technological development, partial dispersion and irretrievable losses of a bigger or smaller share of the used resources, including energy and information that do not materialize in manufactured goods. At the time, Even G. Ford argued that the decomposition of any production processes into separate simple movements causes enormous savings in materials and time. "We try," he stressed," to fight against any kind of waste of human power, time and materials" [16].

The magnitude of these costs is determined by the level of order of the functioning system, reflecting the degree of its order or chaos. They increase with the development of all manifestations of disorder in the system and quickly decrease with the increase of any kinds of structural ordering, striving for a certain minimum-constant, but never in principle can be equal to zero (for example, part of the energy always, regardless of any conditions, will 
simply turn into elementary heat and dissipate, i.e., be lost; material waste of production can never be reduced to zero).

Let's call this possible minimum, for example, a T-constant (T-const). If the costs of economic dissipation are reduced to the value of T-const, or close to it, it means that the economic system and its institutional structure is close to equilibrium as far as it is possible in principle, and effective, and if far from T-const and continue to grow, on the contrary, inefficient and need transformation. In the first approximation, the value of dissipative costs (D) is a function of the above-described conditions:

where:

$$
D=f(T T, O, I)
$$

$T T$ - level of technical and technological development of the company;

$O$ - level of organizational and economic development of the company;

$I$ - the state of the institutional structure of society.

The presence of dissipative costs, in addition to the above, means the fundamental irreversibility, nonlinearity and disequilibrium of any economic, economic and social processes, which in turn, in a sense, already predetermines the possibility or impossibility of forming in the corresponding system of a particular type of institutional ordering and its permissible effectiveness.

The impact of globalization on informal institutions is more complex. First, it is impossible to directly borrow them and introduce them into a different socio-cultural environment, because the criteria for their selection are completely different compared to the formal ones. These criteria can only be the degree of their proximity and compatibility with the national cultural environment, traditions and customs of the borrowing country. And this is not always possible. [17].

Secondly, the impact of globalization on informal institutions encounters some fundamental properties of socio-economic systems-integrity, uncertainty of basic quantitative characteristics, but above all, the property of their self-similarity or fractality [18]. This property consists in invariance of system concerning the majority of transformations and in its ability to keep the maintenance of the basic relations and their relation among themselves, i.e. institutional structure, during indefinitely long time, changing only an external form of manifestation. And because of this, it comes into conflict with the constantly induced by globalization trends towards unity and unification and hinders their development, manifesting itself in practice either in some forms of civil or public disobedience and protest, or in absolute rejection by people and social structures of new global values. Full resolution of this contradiction, as a rule, is impossible even with the total violent restructuring of society on any other value basis and the creation of the necessary mechanisms of coercion. The past will still continue to live in the public consciousness and memory of people, in stories, objects of culture and everyday life, in rites and traditions that persist in spite of everything, gradually becoming mythologized and turning into an object of worship and cult. And in the presence of suitable internal and external conditions, previously operating informal institutions are necessarily partially and sometimes completely restored (history abounds with such examples). This is what happened, for example, with the Institute of religion, actually banned at the time in the USSR, but nevertheless continued to exist for about 70 years and completely restored in modern Russia.

The property of self-similarity, of course, also applies to formal institutions, but in this case the contradiction between them, even if it arises, is resolved easier. The problem can arise only if the formal institution has evolved from the informal, is associated with a deep history and is still intertwined with traditions and culture, that is, if it has actually a hybrid form and structure. 


\subsection{Impact of globalization on the institutional structure of society through the mechanisms of supranational institutions}

The impact of globalization on the institutional structure occurs not only through formal and informal institutions, but also through other mechanisms. A particularly important role here is played by the impact through the new emerging in the context of globalization, previously did not take place at all numerous supranational institutions, interacting both among themselves and with the institutions of individual nation-States [19-21]. They are classified on various grounds, for example, a) by purpose: political; economic; financial (EU - EU, G7 -G7, CSTO, African Union; WTO, OPEC, NAFTA, APEC; IMF, world Bank - WB, IBRD, and many others.); b) by the nature of the distribution of competencies between the nation state and the international supranational organization: institutions that perform only purely coordinating functions; institutions that perform only some of the supranational functions; institutions that are fully supranational entities, etc.

It is obvious that the formation in the process of globalization of such an extensive network of supranational institutions with a variety of both independent and overlapping functions cannot but affect the institutional structure of individual nation States [22]. First of all, they are forced to create a number of new institutions, institutional structures and organizations that are appropriate for their purpose to their international counterparts and are able to effectively address the emerging new challenges of the global world. Secondly, existing institutions are often substantially adjusted, their functions changed or supplemented. Thirdly, some of the existing institutions that do not meet the requirements of the time are being liquidated. Fourth, the relationship between institutions and, accordingly, their role, for example, the degree of dominance in the institutional system, is changing. This influence is to some extent carried out through the mechanisms of convergence of institutions, i.e. mergers or associations of those that perform tasks similar in purpose and purpose, not only at the level of individual countries, but also at the supranational level.

At the same time, it should be noted that the functioning of the supranational global system of institutions and its interaction with the institutional systems of individual States are far from ideal [23]. For example, the creation and strengthening of the role of non-state economic institutions leads to a certain weakening of the role of overlapping with them in many functions of political institutions, as well as inevitably reduces the importance of institutions of nation-States.

Other problems include the practical inability of even such leading supranational institutions as the IMF and the World Bank, among others in conjunction with other global and local institutions, to prevent not only global but also local economic and financial crises. In addition, there is an increasingly visible development of crisis phenomena in the sphere of action of another of the most important global institutions - the world Trade Organization (WTO), whose goals at the time were proclaimed liberalization of international trade relations and regulation of similar relations among its member States. However, at present, contrary to these goals, it is increasingly possible to see the violation of the rules by members of the organization, the strengthening of protectionist policies, the development of trade wars, etc [24]. In addition, currently more markedly observed: the weakening of the political influence of the G7; the discontent of some countries, their role and positions in the IMF and the desire to reorganize their participation in the activities of this organization, etc.

All this, on the one hand, certainly indicates a certain loss of confidence in the ability of modern global institutions to adequately respond to the challenges and needs of the time, and on the other - the possible objective exhaustion of the content of many of them and the need to update it. 


\section{Summary}

The conducted researches allow drawing the following conclusions:

1. The impact of globalization on the institutional structure of society is a complex, multifaceted phenomenon. It is carried out through the mechanisms of numerous and different in nature institutions-formal and informal, national States and supranational.

2. The impact through formal institutions is most rapid and visible. In different countries it is not the same, depending on the initial conditions. It is implemented through various processes, including the import of institutions, their convergence (gradual merger) and institutional diffusion (interpenetration of individual norms), which plays a positive role in the convergence and unification of rules and norms of different countries, thereby increasing the stability and efficiency of their institutional systems.

3. The criterion of efficiency of the new formal institutions can serve, as shown in the work, the costs of economic dissipation, which largely predetermine the very possibility of formation in the economic system of a particular type of structural order and its effectiveness.

4. The impact of globalization on institutional structure through informal institutions is the most complex. It is explained by a particularly high inertia of economic systems to such transformations, because it is associated with centuries-old traditions and customs.

5. The influence on the institutional structure of individual States through the emerging system of global supranational institutions occurs mainly through their interaction with the national institutions of these States. However, it has not only positive, but also serious negative consequences, as it reduces the role and importance of national institutions, and often leads to their destruction. In addition, in recent years, the weakening of both the political and economic influence of supranational institutions has been increasingly evident, which may indicate that their content does not correspond to the needs of the time and the tasks of developing nation-States.

\section{Conclusion}

In conclusion, it seems appropriate to draw attention to the fact that within any national state (society), all of the above institutions, regardless of the characteristics by which they are classified, are closely interrelated and form a single entity that determines the ways of development of this society. S.G. Kirdina called it an institutional matrix [25]. In the structure of this matrix, she highlighted the basic (economic, political, ideological) institutions, which are resistant to any impact of the system of relations and rules of behavior, reproduced throughout the period of existence of society, thus ensuring its survival in historical conditions. So the change or destruction of the system of basic institutions is in fact identical with the disappearance of the corresponding society (state) as a given.

The development of society from the point of view of the concept of institutional matrices is represented as the interaction of two types - matrices X and Y or Eastern and Western, different set of basic institutions. Matrix $X$ is dominated by the institutions of redistributive economy, unitary political structure and collective values, while matrix $\mathrm{Y}$ is dominated by market economy, Federal political structure and individual values. In any society, one of the matrices always dominates, fully defining the content and ways of its development, and the institutions of the other play mainly the role of complementary, increasing the flexibility and adaptability of the institutional system to the external environment and the survival of society.

On the basis of this concept, it is possible to better understand, for example, the complex and contradictory nature of the impact of globalization on the institutional structure of society and the ambiguity of its consequences for different countries. Globalization, as a factor of convergence and unification, through a huge system of supranational institutions 
continuously affects the institutional matrix of individual national States, forming the prerequisites for their transformations. But since the achievements and values of predominantly highly developed countries are spreading throughout the world in the course of globalization, this not only poses no danger to their institutional matrices, but also creates new opportunities for the expansion of these values. While for the underdeveloped, it threatens to erode their institutional structure and, as follows from the above, their very existence.

However, the analysis of the relationship of institutions within institutional matrices is a complex independent problem, which is not the purpose of this article, and can serve as the basis for a new study.

\section{References}

1. N. Rajneesh, C.G. Asmussen, Chi Tailan, S.K. Kundu, Applying and advancing internalization theory: The multinational enterprise in the twenty-first century. Journal of International Business Studies, 50, 1231-1252 (2019)

2. E.R. Banalieva, Ch. Dhanaraj, Internalization theory for the digital economy. Journal of International Business Studies vol.50, 1372-1387 (2019)

3. R.Gabriel, G. Benito, B. Petersen \& L. Welch, "The global value chain and internalization theory." Journal of International Business Studies, Palgrave Macmillan; Academy of International Business, vol. 50(8), 1414-1423 (2019)

4. I. Wallerstein, Globalization or the Age of Transition? A Long-Term View of the Trajectory of the World-System. International Sociology 15(2), 249-265 (2000)

5. A. Giddens, The Consequences of modernity (Stanford, CA: Stanford University Press, 1990)

6. L. Sklair, Sociology of the Global System (Hemel Hempstead, 1991)

7. R. Robertson, Globalization: Social theory and global culture (London: Sage, 2011)

8. U. Beck, Was ist Globalisierung? (Frankfurt a. M, 1998)

9. G.Therborn, Globalizations: dimensions, historical waves, regional effects normative governance. International. Sociology 52, 151-179 (2000)

10. A. Appadurai, Modernity at Large: Cultural Dimensions of Globalization Minneapolis (Minneapolis; London: Univ. of Minnesota Press, 1996)

11. M.Waters, Globalization ( London ; New York : Routledge,1995)

12. V.V. Mironov Transformation of Economics, politics and law under conditions of globalization. Bulletin of Russian Academy of Sciences 86, 99-107 (2016)

13. F. Mikhailov, O. Yurieva, D. Miasnikov, Strategies of the human capital development in conditions of Accelerating diffusion of technical innovation under influence processes of globalization. 18th International Scientific Conference Globalization and Its Socioeconomic Consequences, Rajecke Teplice, Slovak Republic, 2237-2243 (2018)

14. Michael A. Witte, De-globalization: Theories, predictions, and opportunities for international business research. Journal of International Business Studies, 50, 10531077 (2019)

15. D. McCarthy, S. Puffer, D. Satinsky, Will Russia have a role in the changing global economy? Contrasting Western and Russian cultural lenses. Cross Cultural and Strategic Management 26(2), 265-289 (2019)

16. Management is a science and art: A. Fayol, G. Emerson, F. Taylor, G. Ford (Moscow: Republic, 1992) 
17. M. Laroche, L. Teng, Understanding the global consumer culture: Views from eastern and western scholars, an introduction to the special issue. Journal of business research 103, 219-221 (2019)

18. M. Nikolaev, A. Belyakin, Impact of globalization on the sustainable development of economic systems in the context of economic disequilibrium. 16 $6^{\text {th }}$ International Scientific Conference Globalization and Its Socio-economic Consequences Rajecke Teplice, Slovak Republic, 1512-1520 (2016)

19. Michael B. Devereux, Yu. Changhua, International Financial Integration and Crisis Contagion. The Review of Economic Studies, https: //doi.org/10.1093/restud/rdz054 Published: 09 October 2019

20. V. Koval, G. Duginets, O. Plekhanova, On the supranational and national level of global value chain management. Entrepreneurship and sustainability issues 6, 19221937 (2019)

21. M. Copelovitch, J.C.W. Pevehouse, International organizations in a new era of populist nationalism. Review of International Organizations 14(2), 169-186 (2019)

22. M. Butek, E. Spuchlakova, The role of nation state in globalized economy. $17^{\text {th }}$ International Scientific Conference Globalization and Its Socio-economic Consequences, Rajecke Teplice, Slovak Republic, 234-239 (2017)

23. V.A. Ruth, B. Grøgaard, The dubious role of institutions in international business: A road forward. Journal of International Business Studies, Palgrave Macmillan; Academy of International Business 50 (1), 20-35 (2019)

24. N. Williams, The resilience of protectionism in us trade policy. Boston university law review 99, 683-719 (2019)

25. S.G. Kirdina, Institutional matrices and development of Russia: introduction to $X-Y$ theory. 3-rd edition. (SPb.: Nestor-Istoriya, 2014) 